
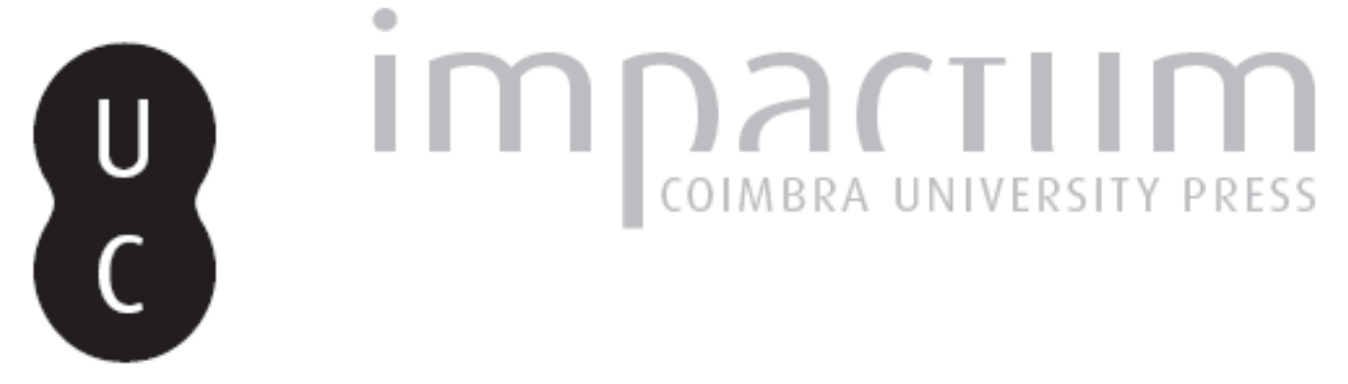

\title{
Muito mais que um mero pretexto
}

Autor(es): Bandeirinha, José António

Publicado por: Editorial do Departamento de Arquitectura

URL persistente:

URI:http://hdl.handle.net/10316.2/37494

DOI:

DOI:http://dx.doi.org/10.14195/0874-6168_6.7-1_2

Accessed : $\quad$ 26-Apr-2023 08:59:21

A navegação consulta e descarregamento dos títulos inseridos nas Bibliotecas Digitais UC Digitalis, UC Pombalina e UC Impactum, pressupõem a aceitação plena e sem reservas dos Termos e Condições de Uso destas Bibliotecas Digitais, disponíveis em https://digitalis.uc.pt/pt-pt/termos.

Conforme exposto nos referidos Termos e Condições de Uso, o descarregamento de títulos de acesso restrito requer uma licença válida de autorização devendo o utilizador aceder ao(s) documento(s) a partir de um endereço de IP da instituição detentora da supramencionada licença.

Ao utilizador é apenas permitido o descarregamento para uso pessoal, pelo que o emprego do(s) título(s) descarregado(s) para outro fim, designadamente comercial, carece de autorização do respetivo autor ou editor da obra.

Na medida em que todas as obras da UC Digitalis se encontram protegidas pelo Código do Direito de Autor e Direitos Conexos e demais legislação aplicável, toda a cópia, parcial ou total, deste documento, nos casos em que é legalmente admitida, deverá conter ou fazer-se acompanhar por este aviso.

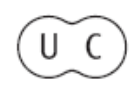




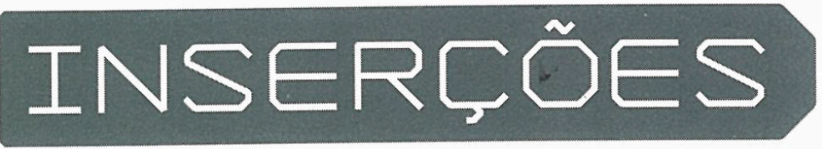

\title{
SEMINÁRIO INTERNACIONAL DE DESENHO URBANO
}

\author{
PT António Belém Lima \\ PT José Gigante \\ ISR Peter Keinan \\ ES Eduard Bru \\ PT Manuel Graça Dias + Egas José Vieira
}
BR MMBB
PT Eduardo Souto Moura
ES Emilio Tuñón + Luis Mansilla
PT Alexandre Alves Costa + Sergio Fernandez
PT Manuel Mateus + Francisco Mateus

\section{(COIMBRA COMO TERRITÓRIO)}

Walter Rossa

(PROJECTOS URBANOS EM COIMBRA )

José António Bandeirinha

(METRO LIGEIRO DE SUPERFICIE)

Gonçalo Byrne, José António Bandeirinha, Nuno Grande, Rui Lobo, Armando Rabaça

( SOBRE UM ELÉCTRICO RÁPIDO )

Paulo Bebiano Correia 


\section{METRO}

MUITO MAIS QUE UM MERO PRETEXTO

José António Bandeirinha

\section{PROJECTOS URBANOS EM COIMBRA, A PARTIR DA INSERÇÃO DO METROPOLITANO LIGEIRO DE SUPERFICIE. MUITO MAIS QUE UM MERO PRETEXTO...}

Perante a iminência de lançamento de um concurso para a implantação de uma rede de metropolitano ligeiro de superfície em Coimbra, apelámos à oportunidade de organizar este seminário sobre as potencialidades da adaptação do espaço urbano a essa mesma rede. Pode parecer um pretexto, mas é muito mais que isso.

Quando, em 2000, lançámos um outro seminário, intitulado "Coimbraum novo mapa", que incidia sobre as possibilidades de intensificação urbana da primeira coroa periférica da cidade, o tema que, verdadeiramente, presidia ao repto então lançado era o da conquista de novas frentes de relacionamento entre as periferias, difusas, irreverentes e fugidias, e o centro, firme, decadente e imobilizado.

A aposta na densificação dessas franjas peri-urbanas revelou-nos a importância de pensar um novo conceito de limite, que se pudesse "tal como Janos, voltar para fora e para dentro, ou criar novas viabilidades, sem fora e sem dentro, mais voltadas para o território indiferenciado da urbe genérica, ou, mais simplesmente, deixar de ser aquilo que são - subúrbios órfãos de núcleo à procura de quaisquer vínculos reais".

Os projectos então realizados permitiam, em conjunto, uma leitura muito clara e eficaz dos processos de catalização nuclear que as novas polaridades poderiam indiciar. A difusão desses pólos, gerados nas últimas décadas em torno da cidade consolidada, só parecia necessitar de alguns mecanismos de coesão, social e física, para que se pudesse potenciar o alastramento em direcção a uma área urbana central, mais vasta e mais homogénea, revalidada precisamente a partir da reflexão sobre os seus próprios limites.
Como partir então para esse novo repto?

Sob o ponto de vista das esferas de decisão, mais político que estratégico, a hipótese do metropolitano ligeiro de superfície surgiu como linha de viabilização económica de infraestruturas ferroviárias obsoletas, ou melhor, infraestruturas ferroviárias não concebidas originariamente para o transporte urbano de passageiros.

Não se tratou de qualquer tipo de intenção geradora de potencialidades infraestruturais, ou de qualquer espécie de empenho na criação de novas práticas de mobilidade. Mas a verdade é que, quando surgiram os primeiros estudos credíveis, ficou muito claro que as potencialidades urbanas deste tipo de transporte são óbvias, ao passo que as suburbanas carecem de um outro tipo de discussão mais aprofundada.

Através desses estudos, o traçado, depois de anos de hesitações, foi-se também optimizando, chegou à solução actual, validando, de resto, um esquema de princípio já existente, de autoria de Paulo Bebiano Correia, concebido, no âmbito académico, entre 1994 e 1996.

Os estudos de inserção de uma infraestrutura de transportes deste tipo, por sua vez, geram sempre motivações fortes, sob o ponto de vista dos projectos urbanos. Acresce, porém, que, no caso de Coimbra, essas motivações são exactamente aquilo que esperávamos para completar a estratégia iniciada. 
Por um lado, temos o tema urbano, em si:

- traseiras ferroviárias esquecidas e degradadas que se podem transformar em frentes altamente qualificadas;

- espaços perdidos que podem vir a ser fortemente polarizados, através da localização das paragens e das suas áreas de influência;

- adaptação de espaços centrais a um tipo diferente de circulação;

- tratamento dos espaços em função dos utentes do transporte e dos peões e não em função do domínio absoluto do automóvel, como tem sido exclusivamente feito atá agora;

- estudo de áreas de comutação com outro tipo de transportes, que podem, e devem, gerar equipamentos essenciais para suprir as carências da cidade.

Por outro lado, mas não menos importante, temos o tema do estabelecimento de um pricípio de coesão uebana para as áreas centrais da cidade, seguindo a ambição que já acima referimos.

Portanto, em lugar de um modelo rectórico, formal ou conceptual, de criação de mecanismos indutores desse reforço identitário das áreas centrais, estávamos perante uma medida estratégica com fortes implicações físicas na estrutura da cidade, mas também com enormes consequências urbanas, sobre os pontos de vista social e ambiental:

- estamos perante a possibilidade de obter um sistema axial de transportes, com implicações fortíssimas nas estratégias de mobilidade para a cidade;

- os efeitos nas deslocações serão tais, que todas as restantes medidas de circulação terão de ser revistas e coordenadas em função dessa nova estratégia;

- trata-se de um transporte colectivo investido de carácter de serviço público, ou, por assim dizer, da colectivização de uma actividade essencial para a vida da cidade, é fácil perceber, portanto, o que é que isso significa, também sob o ponto de vista da coesão social e dos cruzamentos socio-culturais que intensificam e consolidam a vida urbana;

— para além da questão dos transportes, vista dum ângulo meramente funcional, há a considerar um sem número de factores de ordem cultural subjacentes aos fenómenos de identificação dos utilizadores-habitantes com a rede-cidade, como, de resto, é comprovado pela história recente, quando Coimbra ainda tinha uma rede minimamente equilibrada de transportes;
— sob o ponto de vista ambiental, espera-se uma redução significativa do domínio avassalador que o meio de transporte individual tem neste momento. Nesse âmbito, as vantagens são múltiplas e diversificadas, desde a salubrização do ar que respiramos à retoma da escala humana e pedonal nos espaços urbanos centrais;

- a coincidência do centro da rede com os espaços centrais tradicionais, com o hipercentro como se diz em política de transportes, confere novas potencialidades de renovação, económica e urbana, a uma área em acelerada decadência, por efeitos da tercearização excessiva, de falta de investimento e da concorrência da polarização periférica. É necessário saber preparar essas áreas centrais para novos niveis de investimento, comercial, cultural e habitacional. É necessário preparar a Baixa para o seu regresso ao estatuto de centro, não com carácter de exclusividade, mas como núcleo axial de uma área central muito mais vasta.

Estamos, então, perante uma dupla possibilidade de regeneração urbana dos espaços centrais. Por um lado, a intervenção nos espaços, públicos e privados, que a necessária adaptação ao meio de transporte induz. Por outro lado, os efeitos de fortalecimento da coesão dos espaços centrais que um sistema de transportes públicos deste tipo proporciona.

Por outro lado, ainda, a irrefutável clareza física do traçado confere, em linhas gerais, uma possíbilidade única de intervir no desenho do espaço público, de um modo coordenado, sistematizado e hierarquizado. Tomando como ponto de referência esse mesmo traçado, a intervenção nos espaços poderá ser gerida, programada e realizada de um modo racional e eficaz. Ao invés da política habitual - intervenção desgarrada e casuística em áreas escolhidas ao sabor de intuições duvidosas - tem-se agora a oportunidade de agir de modo extensivo, partindo de uma base territorial muito mais coerente.

Desde há quase meio século que, salvo pouquíssimas excepções, o espaço urbano da cidade de Coimbra é produzido exclusivamente em função da circulação automóvel. Projectam-se circulares, variantes e atalhos, que posteriormente vêm a ser resgatadas e bordejadas, de forma atabalhoada, por estruturas habitacionais e terciárias.

Estamos, portanto, perante um momento histórico de altíssimo significado. Pela primeira vez, temos a oportunidade de projectar espaço urbano, de um modo estratégico e abrangente, a partir de uma infraestrutura de inegável utilidade pública.

Saibamos então aproveitar esse ensejo. 


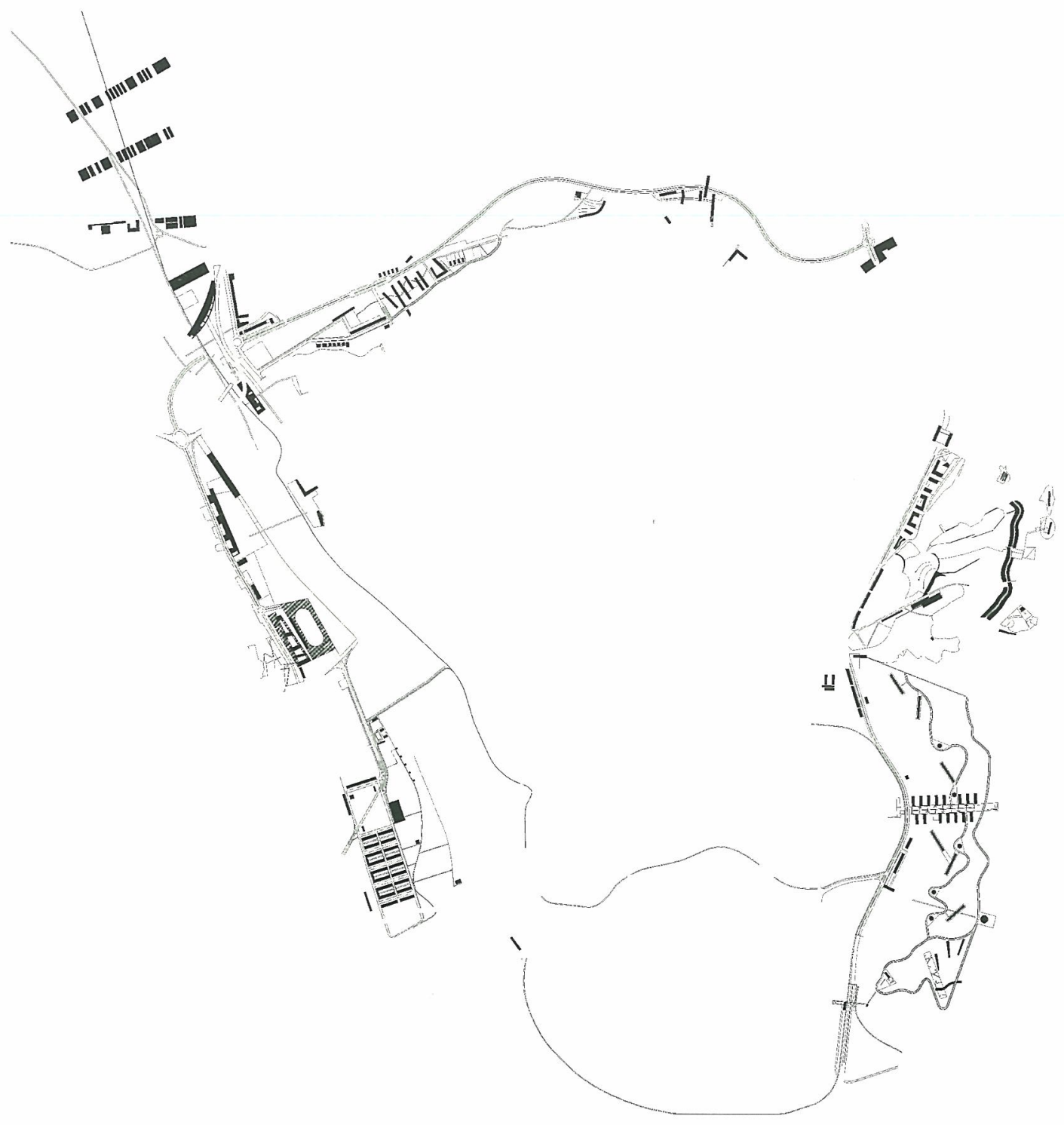


Inserções,

Seminário Internacional de Desenho Urbano

2003

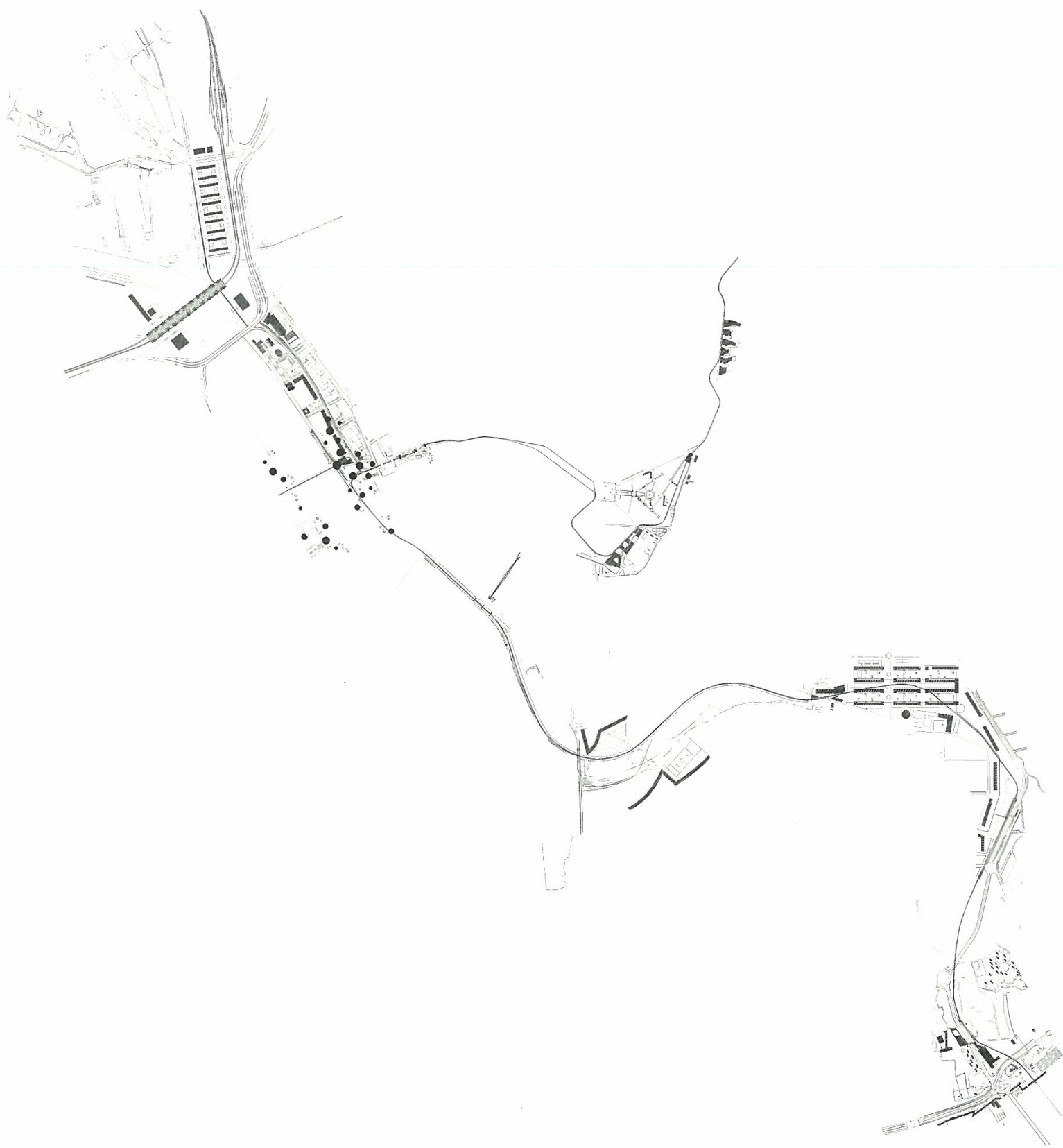

